Original Article

\title{
BANANA PEEL FLAKES ALLEVIATE BLOOD GLUCOSE AND STRESS IN A DOSE-DEPENDENT
} MANNER

\section{ANDREANYTA MELIALA ${ }^{1}$, YUSTINA ANDWI ARI SUMIWI ${ }^{2}$, PARAMITA NARWIDINA ${ }^{3}$, SRI LESTARI SULISTYO RINI ${ }^{1}$, WIDIASTUTI SETYANINGSIH ${ }^{4}$}

${ }^{1}$ Department of Physiology, Faculty of Medicine, Public Health and Nursing, Gadjah Mada University, Jalan Farmako Sekip Utara, Sleman, Yogyakarta 55281, Indonesia, '2Department of Histology, Faculty of Medicine, Public Health and Nursing, Gadjah Mada University, Jalan Farmako Sekip Utara, Sleman, Yogyakarta 5528, Indonesia, ${ }^{3}$ Clinical Nutrition Research Group, Yogyakarta 55133, Indonesia, 4Department of Food and Agricultural Product Technology, Faculty of Agricultural Technology, Gadjah Mada University, Jalan Flora, Bulaksumur, Sleman, Yogyakarta 55281, Indonesia Email: a_meliala@ugm.ac.id

Received: 28 Mar 2020, Revised and Accepted: 19 Jun 2020

\section{ABSTRACT}

Objective: This study aimed to evaluate the antidiabetic and antidepressant effects of banana peel flakes in streptozotocin-induced diabetic rats.

Methods: Twenty-five male Wistar rats were classified into five groups with different treatments. Groups I to IV were diabetic rats model groups that consumed only standard diet, standard diet containing $5 \%, 10 \%$, and $20 \%$ of banana peel flakes, respectively. While group $\mathrm{V}$ was a healthy control group fed a standard diet. Immunohistochemistry staining was measured to examine serotonin expression in the colon and pancreas.

Results: The diabetic rats treated with $20 \%$ banana peel flakes had a lower blood glucose concentration $(p<0.05)$ compared with diabetic control and showed a shorter duration of immobility time $(p<0.05)$ than the healthy control. Additionally, compared with diabetic control, the diabetic rats treated with $5 \%$ banana peel flakes showed higher serotonin expression $(p<0.05)$ in the colon. In contrast, serotonin expression in the pancreas did not show any significant difference $(p>0.05)$.

Conclusion: The present study disclosed that the banana peel flakes provided an antidepressant effect in the diabetic rats model, which might occur through the mechanism of controlling blood glucose concentration.

Keywords: Banana peel, Antidiabetic, Antidepressive, Dietary fiber, Serotonin

(c) 2020 The Authors. Published by Innovare Academic Sciences Pvt Ltd. This is an open access article under the CC BY license (http://creativecommons.org/licenses/by/4.0/) DOI: http://dx.doi.org/10.22159/ijpps.2020v12i8.37659. Journal homepage: https://innovareacademics.in/journals/index.php/ijpps.

\section{INTRODUCTION}

Patients with diabetes have a higher risk of depressive disorders compared with those who suffer from other diseases [1, 2], meanwhile depressed individuals are more vulnerable to metabolic disorders such as diabetes [3]. There is a strong relationship between changes in neuroactive metabolites and depression [4] so that depression is a consequence and risk factor for the development of diabetes. The hyperglycemic condition will trigger oxidative stress caused by the presence of glucose and free fatty acids, which will further encourage the production of reactive oxygen species and stimulate the production of inflammatory mediators such as interleukin-1 (IL-1), interleukin-6 (IL-6) [5], and serotonin [6, 7].

Tryptophan acts as a response to inflammatory conditions. Around $90 \%$ of tryptophan is available [8], and about 3\% of tryptophan catabolism becomes serotonin, while the rest will be degraded by intestinal microflora producing indoles and its derivatives $[9,10]$. This process implies strong competition in using tryptophan between the serotonin and kynurenine synthesis. In inflammatory conditions such as diabetes, tryptophan catabolism for kynurenine will be greater than for serotonin synthesis [11]. A change in the availability of serotonin will cause interference with the digestive tract and brain. At the same time, the presence of tryptophan, which only comes from the diet, will determine the brain's ability to synthesize serotonin [12]

A low tryptophan diet will cause low serotonin concentrations in the central nervous system in human and animal models [13]. Several studies have concluded that microflora in the digestive tract also plays a role in the process of synthesis of serotonin, which will further affect behavior, mood, and anxiety [12, 14]. This fact is related to the significant involvement of microflora in the brain-gut axis function, for which the occurrence of interference in two-way communication will affect the digestive system. In the condition of diabetes, inflammation may cause intestinal dysbiosis [15], which will change the normal microflora community in the digestive tract. These changes affect the regulation of immunity in the intestinal and brain organs and function of the central nervous system [12]. The diversity of intestinal microflora populations is mostly determined by dietary intake that further affects the availability of tryptophan, serotonin, and kynurenine. A good microflora population can be supported by the presence of dietary fiber as a prebiotic. Dietary fiber can be supplied from a wide variety of plants, including yellow kepok banana (Musa balbisiana Colla).

Various food processing made from bananas will produce solid waste in the form of banana peels at $40 \%$ of the weight of fresh bananas. If the waste is not handled correctly, it will cause environmental problems [16]. Banana peels contain a number of chemical compositions that are beneficial to human health, including the complex carbohydrate that triggers the body to secrete insulin and attract some neutral amino acids in the tissues.

The presence of phytochemical compounds, such as flavonoids and tannins, supports the role of banana fruit and peels as an antidiabetic agent $[17,18]$. Flavonoid compounds inhibit glucose absorption in the intestines and increase the activity of $\beta$ cells in the pancreas to secrete insulin [19]. Kepok banana peel (Musa balbisiana Colla) has been recognized to act as an antidepressant and antidiabetic agent [20-22] supported by the content of dietary fiber, amino acid tryptophan, and serotonin-forming precursors. Since the banana peels are perishable, the quality of components and nutrients could rapidly decrease after harvesting. Hence, further careful processing is needed to prolong the shelflife and to minimize the decrease of nutrients in the banana peels.

This study aimed to evaluate the antidiabetic and antidepressant effects of banana peel flakes in streptozotocin-induced diabetic rats. 


\section{MATERIALS AND METHODS}

\section{Banana peel flakes preparation}

The fresh "Kepok Banana" (Musa balbisiana Colla) was purchased from the local market in Sleman, Yogyakarta, Indonesia. The peels were removed and cleaned with water to remove any dirt and unwanted materials. Banana peels were then dipped into water containing $0.5 \%$ citric acid for $10 \mathrm{~min}$; then, the peels were softened by steam blanching in a closed container at $85{ }^{\circ} \mathrm{C}$ for $10 \mathrm{~min}$ Subsequently, the banana peels were blended with water (1:2). Finally, the banana peel flakes were prepared using a drum dryer and grounded to gain the particle size smaller than $1.0 \mathrm{~mm}$.

\section{Mineral and vitamin analysis}

The mineral and vitamin content of the banana peels were analyzed according to the methods of the Association of Official Analytical Chemists [23].

\section{Chemicals}

Streptozotocin (STZ), 5-Hydroxytryptophan, Serotonin, and Antiserotonin developed in rabbits and L-Tryptophan were purchased from Sigma Chemicals Co, St Louis, MO, USA. Fine test rabbit, DAB detection kit, was purchased from Wuhan Fine Biotech, China. All the chemicals used were of analytical grade and gained from Sigma Chemicals Co, St Louis, MO, USA.

\section{In vivo study}

Healthy adult male Wistar rats (Rattus norvegicus) weighing 150$220 \mathrm{~g}$ were used in this study after gained ethical clearance from the Medical and Health Research Ethics Committee, Faculty of Medicine, Universitas Gadjah Mada (Ref: KE/FK/1375/EC/2018; dated $12 / 28 / 2018)$. The animals were housed individually in polypropylene cages under a $12 \mathrm{~h}$ light-dark cycle (light on at 6:00h) and controlled room temperature $\left(22 \pm 2{ }^{\circ} \mathrm{C}\right)$ with free access to cubes of standard diet food and tap water during the experiment. Before starting experimental work, test animals were subjected to one week of acclimation period and various handling procedures to reduce the stress of novelty and handling.

\section{Induction of diabetes in rats}

Wistar rats $(\mathrm{n}=20)$ were injected intraperitoneally with STZ $(60 \mathrm{mg} / \mathrm{kg}$ BW); Sigma-Aldrich, St Louis, MO) diluted in citrate-buffered saline (0.1 $\mathrm{mol} / \mathrm{l}$, pH 4.5; Sigma-Aldrich), as previously described. The rats had free access to $5 \%$ of dextrose during $72 \mathrm{~h}$. twenty rats with blood glucose levels of more than $250 \mathrm{mg} / \mathrm{dl}$ were included in this study.

\section{Experimental design for the study of antidiabetic and} antidepressant-like effects

Different concentrations of banana peel flakes were included in daily food following the grouping: diabetic and non-diabetic control fed a standard diet and the remaining groups received a standard diet containing banana peel flakes with various levels. Male rats were divided into five groups (5 rats each): Group I was served as diabetic control and received a standard diet. Groups II, III and IV were served as diabetic rats and received banana peel flakes 5\%, 10\%, and $20 \%$, respectively. Group V was served as a non-diabetic control group and received a standard diet for three weeks. On the last day, rats were suspended on a horizontal rod $50 \mathrm{~cm}$ above the surface of the table approximately $1 \mathrm{~cm}$ from the tip of the tail (Tail Suspension Test) after $60 \mathrm{~min}$ of the administration of the last various levels of standard diet containing banana peel flakes. The total duration of immobility by tail suspension test was measured to evaluate potential antidepressants. Immobility time was recorded with a webcam during a $6 \mathrm{~min}$ period [24].

\section{Method of blood glucose concentration}

Before blood sampling, each rat was anesthetized using ketamine 70 $\mathrm{mg} / \mathrm{kg} \mathrm{BW}$ on the left or right thigh of the rat. Blood samples were collected from the retro-orbital sinus of each rat for estimation of blood glucose concentration after $72 \mathrm{~h}$ of induced diabetes and then on the $7^{\text {th }}, 14^{\text {th }}$, and $21^{\text {st }}$ days of the experiment. Blood was taken as much as $200 \mu \mathrm{l}$ to $1 \mathrm{ml}$, then was measured using spectro- photometry. Blood glucose was also estimated by the Accu-Check Go glucometer.

\section{Procedure of immunohistochemistry}

Immunohistochemistry (IHC) analysis was performed to visualize and compare the distributions of serotonin in healthy and diabetic rats. Anti-serotonin (Sigma Chemicals Co, St Louis, MO, USA) antibodies and Fine Test rabbit-DAB (Poly-HRP) were used to detect the target proteins in paraffin sections of the colon and pancreas.

\section{Preparation of paraffin sections}

Colon and pancreas samples were collected from rats for histological evaluation. Samples were fixed in $100 \%$ neutral buffered formalin (Merck, Darmstadt, Germany) for $24 \mathrm{~h}$. Samples were gradually dehydrated in $70 \%, 80 \%, 90 \%, 95 \%$ and absolute alcohol for $10 \mathrm{~min}$ each, and immersed in toluene solution for $60 \mathrm{~min}$, following immersion in liquid paraffin $\left(60^{\circ} \mathrm{C}\right.$, for $\left.25 \mathrm{~min}\right)$, and finally embedded in paraffin wax for slide fixation.

\section{Preparation of slides}

Paraffin sections were cut using a rotary manual microtome (Leica RM 2235, United States) and mounted on silane-coated slides (Merck, Darmstadt, Germany) and stored at room temperature.

\section{Antigen retrieval and detection of antigens}

Slides were next deparaffinization in xylene, after rehydrating tissues using graded ethanol, washed with purified water for $2 \mathrm{~min}$, then washed with tris buffered saline (TBS) 3 times for 3 min each. Antigen retrieval was performed in citrate buffer pH 6 for $20 \mathrm{~min}$, and the slides were placed into TBS and then washed by TBS 3 times for $3 \mathrm{~min}$ each. Furthermore, blocking serum was added to the tissue section to block non-specific immunostaining and incubated for $1 \mathrm{~h}$ at $37^{\circ} \mathrm{C}$. Excess blocking serum was blotted from sections.

\section{Secondary detection of the primary antibody}

The sections were incubated for $1 \mathrm{~h}$ at $37^{\circ} \mathrm{C}$, with primary antibody (a rat monoclonal antibody serotonin (5HT), Sigma Chemicals Co, St Louis, MO, USA, working dilution 1:6000 in 10 mmol sodium phosphate, $\mathrm{pH} 7.4,0.9 \%$ saline (PBS)). Slides were washed 3 times for 3 min each with TBS and secondary Antibody Trekkie Universal Link, incubated for $10 \mathrm{~min}$, while secondary antibodies were washed using PBS three times for $5 \mathrm{~min}$. Sections were incubated for $30 \mathrm{~min}$ at $37{ }^{\circ} \mathrm{C}$ with poly-HRP Goat Anti-Rabbit IgG. Furthermore, slides were washed with PBST buffer for $3 \mathrm{~min}$. A solution chromogen, 3,3'-diaminobenzidine (DAB); $1 \mathrm{ml}$ DAB working solution $=50 \mu \mathrm{l}$ of Reagent A, $50 \mu$ l Reagent B, and $900 \mu$ l DAB substrate, available in KITS, was prepared and added to the slides. DAB from the slides was washed with purified water.

\section{Counterstaining}

A solution of hematoxylin Meyer's was diluted with distilled water (1:4) for 1-3 min. The slides were dipped into a hematoxylin solution for staining. Then, slides were washed in running water and dehydrated by dipping in ethanol. Finally, the slides were washed in xylol and mounted in Frontier Duo EFH (Canada) and observed with an Olympus CX21/Optilens Optilab Standard light microscope (Carl Zeiss, Oberkochen, Germany) and photographed with a digital camera.

\section{Allred score determination}

This method has been described in previous research, where the numerical value for overall intensity [intensity score (IS)] was based on a 4-point system: 0, 1, 2, and 3 (for none, light, medium, or dark staining). The numerical value for percent stained [proportion score (PS)] was determined by a geometric $=$ rather than linear division; no stain $=0$; $\leq 1 / 100$ cells stained $=1 ; \leq 1 / 10$ cells stained $=2 ; \leq 1 / 3$ cells stained $=3$, $\leq 2 / 3$ cells stained $=4$; all cells stained $=5$. The addition of the two values gave the total Allred score, so the Allred score can vary between 0 and 8 , although in practice, a score of 1 is precluded [25].

\section{Statistical analysis}

Data in all experiments were presented as means \pm SD. Differences in the measured values and changes in values of body weight, food 
intake, fecal weight, blood glucose and expression of serotonin in the colon were analyzed by non-parametric Mann-Whitney U tests and differences in immobility time duration score and expression of serotonin in the pancreas were analyzed by parametric one-way ANOVA tests followed by LSD post-tests using computerized SPSS software (version 20.0, Chicago, USA). The results were considered statistically significant if the $p$ values were 0.05 or less

\section{RESULTS}

Effect of banana peel flakes on food intake, body weight, and fecal weight

The results of the weight change indicated that after the three weeks treatment period, an increased weight gain was observed in the normal control group, while a decreased weight gain was observed in the diabetic group. The body weight of the diabetic control group was significantly reduced compared to banana peel flakes-treated diabetic rats $(p<0.05)$. The diabetic control group lost $73.94 \mathrm{~g}$ after three weeks of treatment, and diabetic rats treated with banana peel flakes $20 \%$ lost only $11.16 \mathrm{~g}$ (table 1). Furthermore, no significant difference $(p>0.05)$ was observed between the food intake of both normal and diabetic groups. The results of the fecal weight indicate that during the three weeks study period, the fecal weight of banana peel flakes-treated diabetic rats was higher than those of the untreated diabetic rats $(p<0 / 05)$ and revealed a dose-dependent increase $(p<0.05)$

\section{Effect on blood glucose concentration}

Table 2 demonstrates the effect of banana peel flakes on blood glucose in normal and diabetic rats. The results of the statistical analysis indicated that there was a significant difference between the diabetic control group and the banana peel flakes-treated diabetic group. Standard diets containing banana peel flakes at the dose of 5,10 , and $20 \%$ were significantly $(p<0.01)$ reduced the blood glucose levels when compared with a diabetic control group.

Table 1: Bodyweight, food intake and fecal weight of control, STZ-diabetic, and diabetic treated rats after three-week treatment with banana peel flake

\begin{tabular}{lllll}
\hline Groups & Food intake (g/d) & \multicolumn{2}{l}{ Bodyweight (g) } & \multicolumn{2}{l}{$\begin{array}{l}\text { Fecal weight } \\
\text { (g/d) }\end{array}$} \\
\cline { 3 - 5 } & & Initial & Final & Weight changes \\
\hline Diabetic Control & $14.6 \pm 0.5$ & $200.6 \pm 16.9$ & $126.7 \pm 18.4$ & $-73.94 \pm 26.5$ \\
Diabetic+flakes 5\% & $14.2 \pm 1.3$ & $217.8 \pm 45.8$ & $166.8 \pm 44.4^{*}$ & $-51.04 \pm 1.4^{*}$ \\
Diabetic+flakes10\% & $14.7 \pm 0.5$ & $174.7 \pm 18.8$ & $142.0 \pm 25.3$ & $-32.68 \pm 18^{*}$ \\
Diabetic+flakes 20\% & $14.7 \pm 0.5$ & $180.8 \pm 17.1$ & $169.6 \pm 26.5^{*}$ & $-11.16 \pm 16^{*}$ \\
Normal Control & $13.7 \pm 1.4$ & $194.9 \pm 6.8$ & $243.2 \pm 14.3^{* *}$ & $-48.3 \pm 8.3^{* *}$ \\
\hline
\end{tabular}

The values represent the mean \pm SD, Each group consisted of five animals, Experimental groups were statistically compared with the corresponding values of the diabetic control according to multiple comparisons by Mann-Whitney U tests, *Values are statistically significant at $p<0.05$, $* *$ Values are statistically significant at $p<0.01$.

Table 2: Blood glucose concentration in control, STZ-diabetic, and diabetic treated rats after three-week treatment with banana peel flakes

\begin{tabular}{lllc}
\hline Groups & Blood glucose (mg/dl) & & Change in blood glucose \\
\cline { 2 - 4 } & Initial & Final & $51.6 \pm 48.9$ \\
\hline Diabetic Control & $358.8 \pm 29.7$ & $410.4 \pm 36.3$ & $-235.9 \pm 35.3^{* *}$ \\
Diabetic+flakes 5\% & $376.3 \pm 38.6$ & $140.5 \pm 39.3^{* *}$ & $-290.9 \pm 93.8^{* *}$ \\
Diabetic+flakes10\% & $407.2 \pm 38.7$ & $116.3 \pm 40.0^{* *}$ & $-342.9 \pm 80.8^{* *}$ \\
Diabetic+flakes 20\% & $436.7 \pm 79.6$ & $93.8 \pm 8.5^{* *}$ & $11.2 \pm 5.5^{*}$ \\
Normal Control & $95.5 \pm 7.9^{* *}$ & $106.8 \pm 6.9^{* *}$ & \\
\hline
\end{tabular}

The values represent the mean \pm SD, Each group consisted of five animals, Experimental groups were statistically compared with the corresponding values of the diabetic control according to multiple comparisons by Mann-Whitney tests, *Values are statistically significant at $p<0.05$, **Values are statistically significant at $p<0.01$.

Table 3: Tail suspension test in control, STZ-diabetic, and diabetic treated rats after three-week treatment with banana peel flakes

\begin{tabular}{ll}
\hline Groups & Immobility time (s) \\
\hline Diabetic Control & $138.2 \pm 26.27$ \\
Diabetic+flakes 5\% & $134.2 \pm 33.33$ \\
Diabetic+flakes10\% & $111.4 \pm 5.03$ \\
Diabetic+flakes 20\% & $64.4 \pm 22.23^{*}$ \\
Normal Control & $75.0 \pm 20.60^{*}$ \\
\hline
\end{tabular}

The values represent the mean \pm SD, Each group consisted of five animals, Experimental groups were statistically compared with the corresponding values of the diabetic control according to multiple comparisons by LSD tests, *Values are statistically significant at $p<0.05, * *$ Values are statistically significant at $p<0.01$

\section{Effect on the duration of immobility time}

The effect of banana peel flakes on the duration of immobility time is illustrated in table 3. One way ANOVA indicated that there were significant differences between diabetic rats treated with banana peel flakes $20 \%$ and diabetic control group. Rats treated with standard diet containing banana peel flakes $20 \%$ showed a significantly lower duration of immobility time when compared with the diabetic control group.

\section{Effect on serotonin expression in colon and pancreas}

To investigate the expression of serotonin in tissues of normal and diabetic treated rats, IHC analyses were performed. The results indicated that all the groups showed individual cells with positive IHC staining for serotonin both in the colon and pancreas (fig. 1 and fig. 2). Serotonin was expressed at significantly higher levels in the colons from the banana peel flakes $5 \%$-treated diabetic group compared with the diabetic control group $(p<0.05)$ (table 4$)$. 
However, there was not a significant difference in the banana pee flakes $(10 \%$ and $20 \%)$-treated diabetic group compared to the diabetic control group. Based on these results, the diabetic condition may increase serotonin expression in the colon. Furthermore, there were no significantly different expressions of serotonin observed in the pancreas of control and treated diabetic rats (table 5). This result suggests that diabetes did not affect the expression of serotonin in the pancreas.

Table 4: Serotonin immunehistochemical analysis in the colon for control, STZ-diabetic and diabetic treated rats after three-week treatment with banana peel flakes

\begin{tabular}{lllll}
\hline Groups & Proportion score & Intensity score & Allred score & Interpretation \\
\hline Diabetic Control & $4.4 \pm 0.5$ & $2.8 \pm 0.4$ & $7.1 \pm 0.8$ & Strong positive \\
Diabetic+flakes 5\% & $5.0 \pm 0.0$ & $3.0 \pm 0.0$ & $8.0 \pm 0.0^{*}$ & Strong positive \\
Diabetic+flakes10\% & $4.4 \pm 0.5$ & $2.9 \pm 0.3$ & $7.2 \pm 0.7$ & Strong positive \\
Diabetic+flakes 20\% & $4.1 \pm 0.3$ & $2.7 \pm 0.5$ & $6.5 \pm 0.7$ & Intermediate positive \\
Normal Control & $2.7 \pm 0.5$ & $2.2 \pm 0.8$ & $5.0 \pm 1.2^{*}$ & Intermediate positive \\
\hline
\end{tabular}

The values represent the mean \pm SD; Each group consisted of five animals; Experimental groups were statistically compared with the corresponding values of the diabetic control according to multiple comparisons by Mann-Whitney's test; The proportion score included the fraction of positively stained colon was as follows: $0=$ none, $1=1 / 100^{\text {th }} ; 2=1 / 100^{\text {th }}$ to $1 / 10^{\text {th }} ; 3=1 / 10^{\text {th }}$ to $1 / 3 ; 4=1 / 3$ to $2 / 3 ; 5=>2 / 3$. Finally, the two scores (proportion score and intensity score) were combined and the total score of Allred was given. The estimated average staining intensity of the positive cells was expressed as follows; $0=$ none; 1 = weak; 2 = intermediate; $3=$ strong. For the statistical of serotonin expression, the score of $1-3$ was considered low, the score of 4-6 was considered intermediate and the score of 7-8 was considered high. *Values are statistically significant at $p<0.05{ }^{* *}$ Values are statistically significant at $p<0.01$.

Table 5: Serotonin immunohistochemical analysis in the pancreas for control, STZ-diabetic and diabetic treated rats after three-week treatment with banana peel flakes

\begin{tabular}{|c|c|c|c|c|c|}
\hline Parameter & $\begin{array}{l}\text { Diabetic } \\
\text { control }\end{array}$ & $\begin{array}{l}\text { Diabetic +banana peel } \\
\text { flakes } 5 \%\end{array}$ & $\begin{array}{l}\text { Diabetic +banana } \\
\text { peel flakes } 10 \%\end{array}$ & $\begin{array}{l}\text { Diabetic +banana peel } \\
\text { flakes } 20 \%\end{array}$ & $\begin{array}{l}\text { Normal } \\
\text { control }\end{array}$ \\
\hline Proportion score & $2.1 \pm 0.2$ & $2.1 \pm 0.1$ & $2.4 \pm 0.6$ & $2.4 \pm 0.3$ & $1.6 \pm 0.3$ \\
\hline Intensity score & $1.8 \pm 0.2$ & $2.7 \pm 0.1$ & $2.2 \pm 0.5$ & $1.9 \pm 0.2$ & $2.5 \pm 0.4$ \\
\hline Allred score & $4.0 \pm 0.4$ & $4.8 \pm 0.3$ & $4.7 \pm 0.7$ & $4.3 \pm 0.5$ & $4.1 \pm 0.3$ \\
\hline Interpretation & $\begin{array}{l}\text { Intermediate } \\
\text { positive }\end{array}$ & $\begin{array}{l}\text { Intermediate } \\
\text { positive }\end{array}$ & $\begin{array}{l}\text { Intermediate } \\
\text { positive }\end{array}$ & $\begin{array}{l}\text { Intermediate } \\
\text { positive }\end{array}$ & $\begin{array}{l}\text { Intermediate } \\
\text { positive }\end{array}$ \\
\hline
\end{tabular}

The values represent the mean \pm SD; Each group consisted of five animals; Experimental groups were statistically compared with the corresponding values of the diabetic control according to multiple comparisons by LSD test, The proportion score included the fraction of positively stained colon was as follows: $0=$ none, $1=1 / 100^{\text {th }} ; 2=1 / 100^{\text {th }}$ to $1 / 10^{\text {th }} ; 3=1 / 10^{\text {th }}$ to $1 / 3 ; 4=1 / 3$ to $2 / 3 ; 5=>2 / 3$. Finally, the two scores (proportion score and intensity score) were combined and the total score of Allred was given. The estimated average staining intensity of the positive cells was expressed as follows; $0=$ none; $1=$ weak; 2 = intermediate; 3 = strong. For the statistical of serotonin expression, the score of 1-3 was considered low, the score of 4-6 was considered intermediate and the score of 7-8 was considered high. *Values are statistically significant at $p<0.05 .{ }^{* *}$ Values are statistically significant at $p<0.01$.

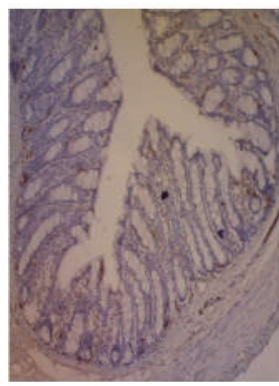

Wenkuätin

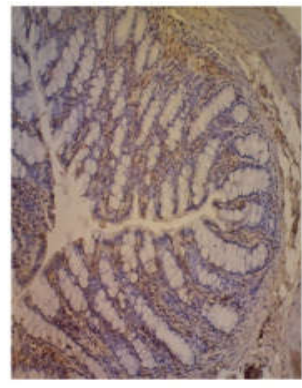

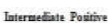

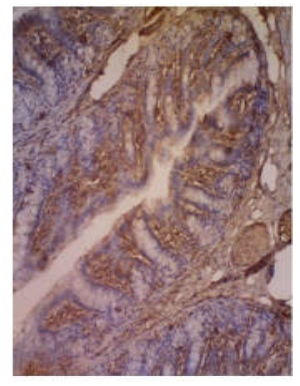

Strong Poustire

Fig. 1: Microscopic photographs of colon stained with IHC, showing weak, intermediate and strong positive serotonin expression

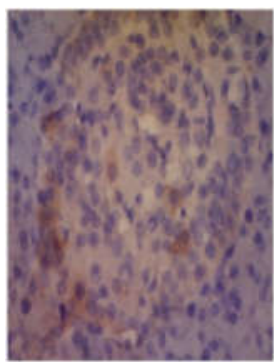

Wusp pruitu

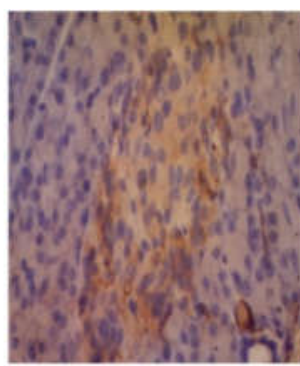

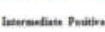

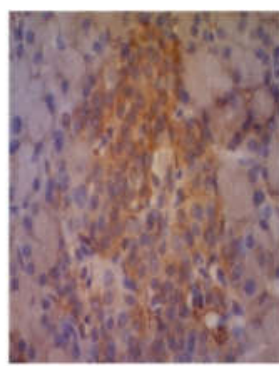

Sines Pustitis

Fig. 2: Microscopic photographs of pancreas stained with IHC, showing weak, intermediate and strong positive serotonin expression 


\section{DISCUSSION}

In the present study, diabetic rats registered a weight loss, while the diabetic control group showed a progressive reduction in body weight. This finding is in agreement with previous research $[26,27]$. The reduction of body weight can be due to the excessive breakdown of tissue proteins in diabetic rats $[27,28]$. Data indicated that the treatment of diabetic rats by Musa balbisiana Colla peel flakes had an inhibitory effect on body weight with a progressive reduction in diabetic rats. The banana peel flakes contain flavonoids, and research has shown that treatment with flavonoids significantly restored reduced body weight [29]. This finding is similar to the previous study about Musa Balbisiana Colla treatment showing it has a positive effect on body weight [21] and demonstrating that there was an inverse relationship between the intake of flavonoids and excess body weight [30].

Banana peels are rich in dietary fiber that could help treat constipation and improve general health [31]. The observed differences in the total weight of feces may be explained by changes to the composition of the diets. This finding has confirmed that diabetic rats group who consumed banana peel flakes that rich in dietary fiber had heavier feces than the control groups (both normal and diabetes-induced with a standard diet). A diet containing dietary fiber can increase bacterial metabolic activity, causing an augmented proliferation of colon mucosa cells [32]. This condition could alter the fecal weight due to their ability to resist dehydration, contrary to the absorptive ability of the colonic mucosa to retain water in the gastrointestinal tract [33].

The diabetic condition is associated with alteration of gut microflora composition and activity [34]. All diabetic mice displayed alterations of the intestinal homeostasis, suggesting that the inflammatory environment may exhibit modifications of intestinal absorptive capacity characterized by an increase of glucose and/or lipid absorption [35, 36], which alters the energetic metabolism. Gut microflora plays an essential role in communication between the enteric and central nervous system, and the integration between nerve, endocrine, and the immune system is known gut-brain axis. Diseases that are linked with glucose metabolic disorders such as diabetes indicate that in the diabetes condition, there is a disruption in the gut-brain axis, and this may lead to the uncontrolled of hyperglycemia and insulin resistance.

There is also another pathway of correlation between gut microflora and metabolic disorders, i.e., the intestinal tract could produce incretins such as Glucagon-Like Peptide-1(GLP-1) or Gastric Inhibitory Polypeptide (GIP) and interestingly, the diabetic mice display an alteration of gut endocrine such as the decrease of GLP-1 and GIP producing cells [10]. Prebiotic treatment in diabetic mice can restore the level of GLP-1 to improve glucose metabolism, and banana is known to have a capacity to improve human health due to its resistant starch. In vitro prebiotic evaluation of bananas resulted in increases in Lactobacillus species populations, and $\mathrm{pH}$ reduction that provides an unfavorable condition for the growth of pathogens [37]. Meanwhile, the fermentation of resistant starch in the large intestines generates short-chain fatty acids (SCFAs), including formic, acetic, propionic, butyric, isobutyric, valeric, isovaleric and caproic acids, thereby reducing the $\mathrm{pH}$ of the colon, which prevents the carcinogenic amines and improves fecal excretion.[38] However, very few data are available about the effect of heating on the prebiotic potential in banana products in modern food processing, i.e., the banana chip process may significantly decrease the availability of resistant starch in the colon.

Lactobacilli and Bifidobacteria spp. were found to flourish in the caecum in other food processing such as raw banana flour, which significantly increased the growth of L. acidophilus in vitro since of presence the resistant starch [37]. Other studies have shown that resistant starch also could improve metabolic health by circulated the inflammatory mediators [39] via bile acids, which may be a potential mechanism to improve glucose homeostatic and insulin resistance [40].

In addition to the above explanations, inflammatory conditions in people with diabetics will cause strong competition between serotonin and the first downstream metabolite of tryptophan, the kynurenine pathway. Therefore, more kynurenine is produced compared to serotonin [41]. If this happens in the brain, it may affect depression then decreased the energy levels [42] and neural plasticity changes due to the formation of AGEs product, vascular dysfunction, and an increase in hypothalamic pituitary adrenal (HPA) axis activity which will cause an increase in cortisol secretion [43]. Cortisol is a glucocorticoid that will work to maintain blood glucose concentration by maximizing liver glucose output so that it could increase blood glucose concentration [44]. All these mechanisms cause diabetic patients who were depressed to have difficulty in controlling blood glucose concentration. Chronic hyperglycemia has been implicated in the onset of diabetes and its complications, and it could induce the production of reactive oxygen species and ultimately lead to oxidative stress and pancreatic cell damage. A strong correlation was observed between vitamin C [45], phenolic content, and radical scavenging activity in the banana cultivar.

In the present study, we have employed the Tail Suspension Test with the intervention of banana peel flakes to analyze the antidepressant-like effects. Our data revealed banana peel flakes dose-dependently diminished the immobility time of diabetic rats, so that banana peel flakes can be looked upon as promising antidepressant medicine. Several studies suggested the possibility that banana peel flakes facilitated serotonergic transmission by inhibition of monoamine oxidase enzyme, and it elevated the concentration of norepinephrine and serotonin in the brain [46]. A previous study showed that rats administered with pulp and peel extract of Musa sapientum had significantly decreased immobility time, as observed in the Forced Swim Test, which indicated an antidepressant-like effect [47]. Formerly, it has been reported that phenolic phytochemicals in banana reduce neurotoxicity [48]. Musa paradisiaca paste reduced the level of malondialdehyde, which indicated a decrease of free radicals, showing that the antioxidant effect of banana fruit may be protecting the brain from oxidative damage [46].

It has been known that serotonin is present in the colon and pancreatic $\beta$ cells, but the physiological role of serotonin in regulating blood glucose concentration is unclear yet. In this study, we demonstrated that the consumption of banana peel flakes for three weeks period was associated with blood glucose concentration and immobility time scores in rats. The expression of serotonin was significantly lower after the consumption of banana peel flakes when compared with the diabetic control group. Earlier studies have demonstrated the decreased concentration of serotonin in mice colons that consumed wholegrain rye intake. Serotonin is produced in the gut by epithelial enterochromaffin cells and brainstem by two distinct rate-limiting enzymes, viz., tryptophan hydroxylase 1 (Tph1) and tryptophan hydroxylase 2 (Tph2), respectively [49]. Increased blood serotonin has been associated with reduced glycemic control, and inhibition of serotonin synthesis in the enterochromaffin cells may reduce metabolic dysfunction and enhance the condition of type 2 diabetes [50]. In the present study, banana peel flakes could significantly decreased serotonin expression in the colons in the diabetic model group in the IHC assay, because banana peel consumption has been linked with enhanced insulin sensitivity and diminishment of metabolic risk factors for type 2 diabetes. Resistant starch in banana peel flakes exerts several beneficial effects by improving insulin resistance and glucose homeostatic both in healthy individuals and those prediabetic individuals with metabolic syndrome [51].

This study found that in the diabetic condition, the expression of serotonin in the colon was higher. This finding is in agreement with a previous report [52], showing it could be a trigger of diabetic complications through contraction of smooth muscle cells in the arterial wall and platelet aggregation [53]. This study also reported that serotonin expression in the pancreas was not significantly different in normal conditions compared to diabetes, and based on these results; diabetic conditions did not inhibit the expression of serotonin. Serotonin was well distributed in the normal group and the pancreas of diabetic rats and has stimulatory effects on insulin secretion from normal pancreatic tissue. Henceforth in the diabetic 
condition, serotonin increased glucagon release in uncontrolled diabetes [54]. In normal conditions, serotonin modulates $\alpha$-cell pancreas function by acting as an inhibitor [55] supporting the hypothesis that banana peel flakes $20 \%$ had an inhibitory effect on glucagon secretion from diabetic pancreatic rats. The consumption of banana peels is beneficial to human health due to the high content of resistant starch, which acts in the body as dietary fiber with slow digestion and lowers glycemic index [56]. The possible mechanisms are the low rate of digestion in the small intestine and the induction of gut hormone release, mainly glucagon-like peptide 1 (GLP-1) and peptide YY (PYY), through the stimulation of intestinal L-cells by short-chain fatty acids (SCFA), and possibly GLP-1 could inhibit glucagon secretion $[57,58]$.

\section{CONCLUSION}

Three weeks of the standard diet intake containing banana peel flakes have a potential antidepressant effect, mainly by suppressing the blood glucose of diabetic rats. In our understanding, the inhibition of intestinal absorption of glucose was proposed as a probable mechanism for the reduction of blood glucose. It may result in the body no longer needing additional insulin to maintain glucose homeostatic. Therefore serotonin expression in diabetic pancreatic tissues was decreased as the plasma and blood glucose decreased. It may conclude that banana peel flakes have an antidepressant effect in the diabetic rat's model, which might occur through the mechanism of controlling blood glucose concentration by the phytochemical compounds. The compounds include antioxidants and tryptophan as precursors for the formation of serotonin and dietary fiber in normalizing the function of the gut-brain axis.

\section{FUNDING}

This research was supported by a grant from the Nutrifood Research Center, 2018

\section{AUTHORS CONTRIBUTIONS}

Andreanyta Meliala: Conceived the study question, and the study design, supervision of data collection, data analysis and interpretation, and writing the manuscript.

Yustina Andwi Ari Sumiwi: Designed the study and contributed to writing the manuscript.

Paramita Narwidina: Wrote the protocol, managed the experimental processes, performed the statistical analysis, and contributed to writing the manuscript.

Widiastuti Setyaningsih: Conducted data collection and data analysis, contributed to data interpretation, and review and editing the manuscript.

Sri Lestari Sulistyo Rini: Conducted data collection and data analysis, and contributed to data interpretation.

\section{CONFLICT OF INTERESTS}

\section{Declared none}

\section{REFERENCES}

1. Anderson R, Freedland $\mathrm{K}$, Clouse $\mathrm{R}$. The prevalence of comorbid depression in adults with diabetes: a meta-analysis. Diabetes Care 2001;24:1069-78.

2. Ali N, Jyotsna V, Kumar N. Prevalence of depression among type 2 diabetes compared to healthy non-diabetic controls. J Assoc Physicians India 2013;61:619-21.

3. Roy T, Lloyd C. Epidemiology of depression and diabetes: a systematic review. J Affect Disord 2012;142:S8-21.

4. Oxenkrug GF. Metabolic syndrome, age-associated neuroendocrine disorders, and dysregulation of tryptophankynurenine metabolism. Ann NY Acad Sci 2010;1199:1-14.

5. Banerjee M, Saxena M. Interleukin-1 (IL-1) family of cytokines: role in type 2 diabetes. Clin Chim Acta 2012;413:1163-70.

6. Shajib MS, Baranov A, Khan WI. Diverse effects of gut-derived serotonin in intestinal inflammation. Chem Neurosc 2017;8:920-31.
7. Costedio MM, Hyman N, Mawe GM, et al. Serotonin and its role in the colonic function and in gastrointestinal disorders. Dis Colon Rectum 2014;50:376-88.

8. Waclawikov B, Aidy S El. Role of microbiota and tryptophan metabolites in the remote effect of intestinal inflammation on brain and depression. Pharmaceuticals 2018;25:1-17.

9. Badawy AA. Modulation of tryptophan and serotonin metabolism as a biochemical basis of the behavioral effects of use and withdrawal of androgenic-anabolic steroids and other image and performance-enhancing agents. Int J Tryptophan Res 2018;11:1-16.

10. Richards P, Pais R, Habib A. High-fat diet impairs the function of glucagon-like peptide-1, producing L-cells. Peptides 2016;77:21-7.

11. Keszthelyi D, Troost F, Jonkers D. Does acute tryptophan depletion affect peripheral serotonin metabolism in the intestine? Am J Clin Nutr 2012;95:603-8.

12. Dehhaghi M, Kazemi H, Panahi S. Microorganisms, tryptophan metabolism, and kynurenine pathway: a complex interconnected loop influencing human health status. Int J Tryptophan Res 2019;12:1-10.

13. Clarke G, Grenham SPS. The microbiome-gut-brain axis during early life regulates the hippocampal serotonergic system in a sex-dependent manner. Mol Psychiatry 2013;18:666-73.

14. Kwon YH, Wang H, Denou E. Modulation of gut microbiota composition by serotonin susceptibility to colitis. Cell Mol Gastroenterol Hepatol 2019;7:709-28.

15. Cani PD, Osto M, Geurts L. Involvement of gut microbiota in the development of low-grade inflammation and type 2 diabetes associated with obesity. Gut Microbes 2012;3:279-88.

16. Nagarajaiah SB, Prakash J. Chemical composition and antioxidant potential of peels from three varieties of banana. Asian J Food Agro-Industry 2011;4:31-46.

17. Lewis D, Shaw G. A natural flavonoid and synthetic analogues protect the gastric mucosa from aspirin-induced erosion. J Nutr Biochem 2001;12:95-100.

18. Kusuma SF, Mita SR, Firdayani. Study on the antibacterial activity of fruit extracts of klutuk banana (musa balbisiana colla) against Shigella dysenteriae atcc 13313. Asian J Pharm Clin Res 2017;10:220-3.

19. Someya S, Yoshiki Y, Okubo K. Antioxidant compounds from bananas (Musa cavendish). Food Chem 2002;79:351-4.

20. Gopalan G, Prabha B, Joe A. Screening of Musa balbisiana colla. Seeds for antidiabetic properties and isolation of apiforol, a potential lead, with antidiabetic activity. J Sci Food Agric 2018;99:1-31.

21. Borah M, Das S. Antidiabetic, antihyperlipidemic, and antioxidant activities of musa balbisiana colla. in type 1 diabetic rats. Indian J Pharmacol 2017;49:71-6.

22. Purabi D, Ananya K, Daisy S. A review on Musa Balbisiana colla. Int J Pharm Sci Invent 2018;7:14-7.

23. Official methods of analysis of the Association of Official Analytical Chemists. In: AOAC. Gaithersburg MD, USA; 2005. p. 18.

24. Alam S, Ehsan SD. Antidepressant-like activity of banana peel extracts in mice. Tan pei tee and halijah hassan. Am J Med 2011;2:59-64.

25. Chand P, Garg A, Singla V. Evaluation of an immunohistochemical profile of breast cancer for prognostics and therapeutic use. Niger J Surg 2018;24:100-6.

26. Navghare V, Shashikant D. Suppression of type-II diabetes with dyslipidemia and nephropathy by peels of Musa cavendish fruit. Ind J Clin Biochem 2016;31:380-9.

27. Saad EA, Hassanien MM, El-hagrasy MA, Radwan KH. Antidiabetic, hypolipidemic and antioxidant activities and protective effects of punica granatum peels powder against pancreatic and hepatic tissues injuries in streptozotocininduced iddm in rats. Int J Pharm Pharm Sci 2015;7:397-402.

28. Andallu B, Varadacharyulu NC. Antioxidant role of mulberry (Morus indica L. cv. Anantha) leaves in streptozotocin-diabetic rats. Clin Chim Acta 2003;338:3-10.

29. Jain D, Bansal M, Dalvi R. Protective effect of diosmin against diabetic neuropathy in experimental rats. J Integr Med 2014;12:35-41. 
30. Balbi MDA, Crivellenti LC, Cristina D. The relationship of flavonoid intake during pregnancy with excess body weight and gestational diabetes mellitus. Arch Endocrinol Metab 2019;63:241-9.

31. Singh A, Singh S. Dietary fiber content of Indian diets. Asian J Pharm Clin Res 2015;8:58-61.

32. Gestel G, Besançon P. Comparative evaluation of the effects of two differents forms of dietary fibre (Rice bran vs wheat bran) on rat colonic mucosa and fæcal micro-flora. Ann Nutr Metab 1994;38:249-56.

33. Vries J De, Birkett A, Hulshof T. Effects of cereal, fruit and vegetable fibers on human fecal weight and transit time: a comprehensive review of intervention trials. Nutrients 2016;8:1-10.

34. Everard A, Geurts L, Caesar R. Intestinal epithelial MyD88 is a sensor switching host metabolism towards obesity according to nutritional status. Nat Commun 2014;5:1-12.

35. Ferraris RP, Vinnakota RR. Intestinal nutrient transport in genetically obese mice. Am J Clin Nutr 1995;62:540-6.

36. Mao J, Hu X, Xiao Y, Yang C, Ding Y, Hou N, et al. Overnutrition stimulates intestinal epithelium proliferation through betacatenin signaling in obese mice. Diabetes Metab Res Rev 2013;62:3736-46.

37. Mahore JG, Shirolkar SV. Investigation of the effect of ripening and processing on the prebiotic potential of banana. J Young Pharm 2018;10:10-4.

38. Topping DL, Clifton PM. Short-chain fatty acids and human colonic function: roles of resistant starch and non-starch polysaccharides. Physiol Rev 2001;81:1031-64.

39. Ble Castillo JL, Juarez Rojop IE, Tovilla Zarate CA. Acute consumption of resistant starch reduces food intake but has no effect on appetite ratings in healthy subjects. Nutrients 2017;9:1-12.

40. Bindels L, Walter J, Ramer Tait A. Resistant starches for the management of metabolic diseases. Curr Opin Clin Nutr Metab Care 2015;18:559-65.

41. Catena Dell'Osso M, Rotella F, Dell'Osso A. Inflammation, serotonin and major depression. Curr Drug Targets 2013;14:571-7.

42. Gal E, Sherman A. L-Kynurenine: its synthesis and possible regulatory function in brain. Neurochem Res 1980;5:223-9.

43. Gkogkolou P, Böhm M. Advanced glycation end products key players in skin aging? Dermatoendocrinol 2012;4:3:259-70.

44. Kamba A, Daimon M, Murakami H. Association between higher serum cortisol levels and decreased insulin secretion in a general population. PLoS One 2016;11:1-10.
45. Adedayo BC, Oboh G, Oyeleye SI. Antioxidant and antihyperglycemic properties of three banana cultivars (Musa spp.). Scientifica 2016:1-7. https://doi.org/10.1155/ 2016/8391398.

46. Fidrianny I, Rizki Kiki R, Insanu M. In vitro antioxidant activities from various extracts of banana peels using abts, dpph assays and correlation with phenolic, flavonoid, carotenoid content. Int J Pharm Pharm Sci 2014;6:299-303.

47. Samad N, Ullah N, Ayaz MM. Banana fruit pulp and peel involved in antianxiety and antidepressant effects while invigorate memory performance in male mice: possible role of potential antioxidants. Pak J Pharm Sci 2017;30:989-95.

48. Debjit Bhowmik KP, Sampath Kumar, M Umadevi. Traditional and medicinal uses of banana. J Pharmacogn Phytochem 2012;1:51-63.

49. Martin AM, Young RL, Leong L. The diverse metabolic roles of peripheral serotonin. Endocrinology 2017;158:1049-63.

50. Crane JD, Palanivel R, Mottillo EP. Inhibiting peripheral serotonin synthesis reduces obesity and metabolic dysfunction by promoting brown adipose tissue thermogenesis. Nat Med 2014;21:1-9.

51. Bodinham C, Smith L, Thomas E. Efficacy of increased resistant starch consumption in human type 2 diabetes. Endocr Connect 2014;3:75-84.

52. Takahashi T, Yano M, Minami J. Sarpogrelate hydrochloride, a serotonin2A receptor antagonist, reduces albuminuria in diabetic patients with early-stage diabetic nephropathy. Diabetes Res Clin Prac 2002;58:123-9.

53. Malyszko J, T Urano, R Knofler. Daily variations of platelet aggregation in relation to blood and plasma serotonin in diabetes. Thromb Res 1994;75:569-76.

54. Adeghate E, Ponery AS, Pallot D. Distribution of serotonin and its effect on insulin and glucagon secretion in normal and diabetic pancreatic tissues in rat. Neuro Endocrinol Lett 1999;20:315-22.

55. Marco J, Hedo JA, Villanueva ML. Inhibition of glucagon release by serotonin in mouse pancreatic islets. Diabetologia 1977;13:585-8.

56. Rodriguez Ambriz, Agama Acevedo I, Etovar J. Characterization of a fiber-rich powder prepared by liquefaction of unripe banana flour. Food Chem 2008;4:1515-21.

57. Kim W, Egan JM. The role of incretins in glucose homeostasis and diabetes treatment. Pharmacol Rev 2008;60:470-512.

58. Ramracheya R, Chapman C, Chibalina M. GLP-1 suppresses glucagon secretion in human pancreatic alpha-cells by inhibition of P/Q-type Ca 2+channels. Physiol Rep 2018;6:1-17. 